\title{
TESTAMENTAL VITAL: CONSIDERAÇÕES ACERCA DE SUA (IM)POSSIBILIDADE NO BRASIL
}

\author{
Marcus Vinícius Dellavalle Dutra* \\ Daiane Pereira Araújo***
}

\begin{abstract}
RESUMO
0 presente artigo dedica-se a tecer considerações acerca da Resolução n. 1.995, de 2012, do Conselho Federal de Medicina, que introduziu as diretivas antecipadas de vontade ou testamento vital, como também são conhecidas. Temática que ainda não foi regulamentada por lei específica no Brasil, mas que tem gerado bastante polêmica no meio jurídico. Tratase de possibilidade conferida aos pacientes para, previamente, manifestarem-se acerca de eventuais tratamentos médicos que desejam, ou não, se submeter, quando estiverem impossibilitados de exprimir sua própria vontade. Para melhor compreender a importância do testamento vital para os brasileiros, far-se-á breves considerações sobre as modalidades de testamentos existentes no ordenamento, discorrendo, posteriormente, também sobre as inovações trazidas por esta resolução para ao fim e ao cabo, realizar ponderações sobre a Ação Civil Pública proposta pelo Ministério Público face ao Conselho Federal de Medicina, questionando a sua constitucionalidade.
\end{abstract}

PALAVRAS-CHAVE: Diretivas Antecipadas de Vontade; Testamento Vital; Ação Civil Pública; Constitucionalidade.

* Bacharel em Direito pela Universidade de Passo Fundo - UPF. Especialista em Direito Municipal pela Universidade de Passo Fundo. Professor Universitário. Advogado.

** Pós-graduanda em Direito de Família Contemporâneo e Mediação pela FADERGS. Bacharel em Direito pelo Centro Universitário Metodista, do IPA. Mediadora Judicial em Formação. Advogada. 


\begin{abstract}
This article is dedicated to some considerations about the Federal Council of Medicine's Resolution no. 1.995, 2012, which introduced the advance directives of will or living will. Issue not regulated by specific law in Brazil but which has generated enough controversy in the legal environment. It is possibility for patients to previously choose about any medical treatment they want to submit when are unable to express their own will. To understand the importance of living wills for the Brazilians, shall be made-brief remarks on the modalities of existing wills, also on the innovations brought by this resolution to the end to deal with prosecutors' Public Civil Action against the Federal Council of Medicine, questioning resolution constitutionality.
\end{abstract}

KEYWORDS: Advance Directives Will; Living Will; Public Civil Action; Constitutionality.

\title{
1. INTRODUÇÃO
}

Por testamento, para fins de mera introdução, em breves e sucintas linhas, poder-se-ia dizer que é o ato praticado por alguém em vida, com vistas a disposição de seu patrimônio e outras estipulações aceitas pela legislação, para que produzam efeitos após a sua morte.

No Brasil, até 2012, existiam apenas seis possibilidades de testamentos, sendo três testamentos ordinários (público, cerrado e particular) e três testamentos especiais (militar, marítimo e aeronáutico).

Os testamentos ordinários são revestidos de formalidades, cujo objetivo é o de dar maior segurança e seriedade as disposições de última vontade do testador acerca da destinação de seus bens, podendo este, dispor, no todo ou em parte, do seu patrimônio.

Os testamentos especiais, por sua vez, são formas mais emergenciais que também são revestidos de formalidades, entretanto, são aceitos com menos formalidades do que os ordinários, existindo, inclusive, a possibilidade de testar oralmente, que permite que as pessoas possam dispor sobre o seu patrimônio 
quando estiverem em situação de guerra ou a bordo de navios ou, ainda aeronaves, dispensando a presença de um tabelião ou seu substituto.

Contudo, em 2012 o Conselho Federal de Medicina publicou a Resolução n. 1995 em que dispôs sobre as diretivas antecipadas de vontade ou testamento vital, como também são conhecidas pela doutrina.

Trata-se da possibilidade de pacientes manifestarem seus desejos, prévia e expressamente, sobre cuidados e tratamentos que quer, ou não, receber no momento em que estiverem incapacitados de expressar, livre e autonomamente, sua própria vontade.

0 testamento vital é realidade em várias legislações alienígenas, tais como Portugal, Espanha, Bélgica, Estados Unidos. No Brasil, porém, ainda não há legislação específica sobre o tema, em que pese seja uma realidade presente na vida de pacientes e médicos há algum tempo enquanto fato.

Em razão da omissão do legislativo, optou o Conselho Federal de Medicina por orientar os médicos, através da Resolução n. 1.995 de 2012, acerca dos procedimentos que devem adotar quando se depararem com eventuais manifestações de vontade de pacientes e familiares, de modo a respeitar a autonomia privada destes.

Trata-se de tema que ainda não é pacificado no meio jurídico em razão do entendimento de que não se trata de disposição de última vontade, uma vez que pode ou não ocorrer o evento morte, diferente do que ocorre nas modalidades de testamentos então expressamente previstas no ordenamento jurídico pátrio, onde a morte do testador é condição jurídica - suspensiva - para que o ato volitivo praticado em vida passe a produzir seus efeitos jurídicos.

Para melhor entender a discussão acerca da possibilidade jurídica ou não de pacientes poderem utilizar as diretivas antecipadas de vontade ou testamento vital, abordar-se-á as modalidades de testamentos previstos no ordenamento até 2012, bem 
como as peculiaridades introduzidas pela Resolução n. 1.995 de 2012. Por fim, verificar-se-á os principais pontos atacados pelo Ministério Público Federal na Ação Civil Pública em questiona a constitucionalidade da referida resolução.

\section{DAS MODALIDADES DE TESTAMENTOS PREVISTOS NO ORDENAMENTO}

De acordo com Ribeiro ${ }^{1}$ testamento "é o ato personalíssimo e revogável pelo qual alguém, de conformidade com a lei, não só dispõe, para depois de sua morte, no todo ou em parte, do seu patrimônio, mas também faz estipulações."

O Código Civil Brasileiro de 2002 não estabeleceu um conceito do que seria testamento, mas dispôs em seu artigo 1.857 que "toda pessoa capaz pode dispor, por testamento, da totalidade dos seus bens, ou de parte deles, para depois de sua morte". No artigo $1.858^{2}$ dispôs também que "o testamento é ato personalíssimo, podendo ser mudado a qualquer tempo." 3

A capacidade testamentária, colocada como requisito na legislação para que a pessoa possa testar, divide-se entre ativa e passiva, referindo-se a primeira a quem pode testar e a segunda a quem pode ser beneficiado pelo testador. (GONÇALVES, 2009, p. 212)

0 artigo 1.960 da Codificação Civil diz quem está impedido de testar (capacidade ativa), assim dispondo "além dos incapazes, não podem testar os que, no ato de fazê-lo, não tiverem pleno discernimento." Ainda, no seu parágrafo único afirma que "podem testar os maiores de dezesseis anos." Excluindo-se as pessoas que

1 RIBEIRO, Regis Rezende. Testamentos e codicilos. Disponível em http:// regisrezenderibeiro.jusbrasil.com.br/artigos/115241919/testamentos-ecodicilos. Acesso realizado em 10 de janeiro de 2016.

2 BRASIL, Código Civil Brasileiro de 2002. Art. 1.858. 0 testamento é ato personalíssimo, podendo ser mudado a qualquer tempo.

3 BRASIL, Código Civil Brasileiro de 2002. Art. 1.857. Toda pessoa capaz pode dispor, por testamento, da totalidade dos seus bens, ou de parte deles, para depois de sua morte.

4 BRASIL, Código Civil Brasileiro de 2002. Art. 1.860. Além dos incapazes, não podem testar os que, no ato de fazê-lo, não tiverem pleno discernimento. Parágrafo único. Podem testar os maiores de dezesseis anos. 
são impedidas de testar pela legislação, em princípio, as demais estão aptas a fazê-lo.

Já a capacidade testamentária passiva versa sobre as pessoas que não podem ser beneficiadas pelo testador, tendo sido arroladas no Art. 1.801, conforme se verifica:

Art. 1.801. Não podem ser nomeados herdeiros nem legatários: I - a pessoa que a seu rogo, escreveu o testamento, nem o seu cônjuge ou companheiro, ou seus ascendentes e irmãos; II - as testemunhas do testamento; III - o concubino do testador casado, salvo se este, sem culpa sua, estiver separado de fato do cônjuge há mais de cinco anos; IV - o tabelião, civil ou militar, ou o comandante ou escrivão, perante quem se fizer, assim como o que fizer ou aprovar o testamento.

Explicado o conceito de testamento e capacidade testamentária, passaremos a tratar das principais características dos testamentos que são: a) ato personalíssimo; b) negócio jurídico unilateral; c) ato solene; d) ato gratuito; e) é revogável e; f) só produz efeito após a morte do testador, conforme trecho abaixo, senão vejamos:

As principais características do testamento são: a) É um ato personalíssimo: privativo do autor da herança, não se admite sua feitura por procuração nem mesmo com poderes especiais; b) Constitui um negócio jurídico unilateral: isto é, aperfeiçoa-se com uma única manifestação de vontade, a do testador, e presta-se à produção de diversos efeitos por ele desejados e tutelados na ordem jurídica; c) É solene: só terá validade se forem observadas todas as formalidades essenciais prescritas na lei. Não podem elas serem postergadas, sob pena de nulidade do ato. d) É um ato gratuito: pois não visa obtenção de vantagens para o testador. e) É revogável: pode o testador usar o direito de revogá-lo total ou parcialmente, quantas vezes quiser, salvo na parte em que o testador tenha reconhecido um filho havido fora do patrimônio. f) É um ato causa mortis: produz efeitos apenas após a morte do testador. ${ }^{5}$

5 RIBEIRO, Regis Rezende. Testamentos e codicilos. Disponível em http:// regisrezenderibeiro.jusbrasil.com.br/artigos/115241919/testamentos-ecodicilos. 
Logo, para que o testamento seja considero válido é preciso respeitar os requisitos estabelecidos pela legislação vigente, tais como a capacidade testamentária e as características do ato, caso contrário, considerar-se-ão sem efeitos as disposições do testador.

A legislação brasileira admitiu no ordenamento apenas três formas de testamentos ordinários: o testamento público, o cerrado e o particular. ${ }^{6}$

O testamento público é aquele que é "escrito pelo tabelião em seu livro de notas, de acordo com as declarações do testador, feitas em língua nacional, podendo este servir-se de minuta, notas ou apontamentos, em presença de duas testemunhas, que devem assistir todo o ato." (GONÇALVES, 2009, p. 232)

De acordo com Dias, o legislador não logrou êxito em definir o conceito de testamento público, mas apontou suas características, conforme se verifica no trecho abaixo (DIAS, 2013, p. 366):

A lei não define o testamento público, mas aponta suas características essenciais (CC 1.864), cuja obediência estrita é da substância do ato. A preterição de qualquer das formalidades legais o fulmina de nulidade insanável. É exigida: a) a presença do próprio testador; b) sua declaração de vontade ao tabelião; c) ser escrito pelo tabelião em seu livro de notas, de acordo com as declarações do testador; d) ser lido em voz alta pelo tabelião ou pelo testador, na presença de duas testemunhas; e; e) assinatura de todos os presentes.

O testamento cerrado7, "também chamado secreto ou místico, é escrito pelo próprio testador, ou por alguém a seu rogo, só tendo eficácia após o auto de aprovação lavrado por oficial público, na presença de duas testemunhas".

6 BRASIL, Código Civil Brasileiro de 2002, Art. 1.862 São testamentos ordinários: I - o público; ll - o cerrado e; III - o particular. Disponível em http:// www.planalto.gov.br/ccivil_03/leis/2002/L10406.htm.

7 RIBEIRO, Regis Rezende. Testamentos e codicilos. Disponível em http:// regisrezenderibeiro.jusbrasil.com.br/artigos/115241919/testamentos-ecodicilos. 
Abate $^{8}$ explica que para que o testamento cerrado seja considerado válido é necessário também observar as formalidades exigidas pela legislação, conforme se vê:

0 testamento cerrado, por sua vez, é aquele escrito pelo testador, ou por outra pessoa de sua escolha, por aquele assinado e somente terá validade se aprovado pelo tabelião ou por seu substituto legal observadas as seguintes formalidades: i) que o testador entregue ao tabelião na presença de duas testemunhas; ii) que o testador declare que aquele é o seu testamento e quer que seja aprovado; iii) que o tabelião lavre o auto de aprovação na presença das duas testemunhas e o leia em seguida, iv) que o auto de aprovação seja assinado pelo tabelião, pelas testemunhas e pelo testador.

O testamento particular, por sua vez, "também chamado de privado, aberto, do próprio punho - é conhecido por uma palavra horrível: hológrafo ou ológrafo, expressão que vem do grego e significa escrito inteiro, completo." (DIAS, 2013, p. 372)

0 testamento privado é aquele que só pode ser escrito de próprio punho ou através de processo mecânico e assim como os demais, para que seja considerado válido é necessário observar, rigorosamente, as suas formalidades, conforme alerta Abate $^{9}$ :

[...] o testamento particular é aquele que só pode ser escrito de próprio punho ou mediante processo mecânico. Se elaborado de próprio punho, são requisitos de essenciais à sua validade, que seja lido e assinado por quem o escreveu, na presença de pelo menos três testemunhas que o devem subscrever. Se elaborado por processo mecânico não pode conter rasuras ou espaços em branco, devendo ser assinado pelo testador depois de ter lido na presença de pelo menos três testemunhas que também o subscreverão.

Além dos testamentos ordinários acima conceituados, o legislador brasileiro optou ainda por inserir outras três modalidades deste instituto, chamados de especiais: a) o testamento militar; b) o marítimo e, c) o aeronáutico.

8 ABATE, Alessandra. Os tipos de testamento. Disponível em http://correiadasilva.com.br/pdf/art_fam/art_fam4.pdf.

9 ABATE, Alessandra. Os tipos de testamentos. Disponível em http://correiadasilva.com.br/pdf/art_fam/art_fam4.pdf. 
O testamento militar é a "declaração de última vontade feita por militares e demais pessoas a serviço do Exército, dentro ou fora do País, que estejam participando de operações de guerra [...].”(DIAS, 2013, p. 379). Para que este testamento seja utilizado é necessário que haja efetivamente a situação de guerra e não pode existir no local qualquer tabelião ou substituto. Se houver algum tabelião ou substituto, deverá o militar optar pelas formas de testamentos ordinários, uma vez que este testamento, assim o marítimo e aeronáutico justificam-se em razão da urgência e da dispensabilidade de algumas formalidades que são atribuídas aos testamentos ordinários. (DIAS, 2013, p. 379).

Para Dias, mesmo optando pelo testamento militar suas formas podem ser semelhantes ao testamento público, ao cerrado e ao nuncupativo ${ }^{10}$, conforme trecho abaixo (DIAS, 2013, p. 379):

0 testamento militar pode ser levado a efeito de três maneiras: de forma semelhante ao testamento público (CC 1.893), cerrado (CC 1.894) ou nuncupativo (CC 1.896). A especialidade desses testamentos diz somente com a forma, que é simplificada. Quanto ao conteúdo e aos efeitos, não há diferença em relação aos testamentos ordinários. Porém, nada impede seja feito o testamento particular (CC 1.876) e até o excepcional (CC 1.879).

O testamento marítimo é a disposição de última vontade feita "a bordo de navio nacional, de guerra ou mercante", realizada perante o comandante do navio e na presença de duas testemunhas, conforme definição do Código Civil. ${ }^{11}$

10 Testamento nuncupativo não é escrito, é realizado inteiramente de forma verbal onde o testador que estiver ferido ou em combate irá falar para duas testemunhas qual a sua última vontade e, após sua morte, as testemunhas deverão procurar o oficial da patente para que este reduza a termo as declarações e enfim a assinem. Disponível em http://www.webartigos.com/ artigos/especies-de-testamento/40014/.

11 BRASIL, Código Civil Brasileiro de 2002. Art. 1.888. Quem estiver em viagem, a bordo de navio nacional, de guerra ou mercante, pode testar perante o comandante, em presença de duas testemunhas, por forma que corresponda ao testamento público ou ao cerrado. Disponível em http://www.planalto. gov.br/ccivil_03/leis/2002/L10406.htm. 
Assim como o testamento militar, o testamento marítimo poderá assumir forma assemelhada ao testamento público ou cerrada e deve, necessariamente, observar os seguintes requisitos:

A validade do testamento marítimo requer: a) que a viagem se realize em navio nacional, pois este é considerado extensão do território nacional, ainda que se encontre em águas internacionais ou portos de outros países; b) que se trate de navio de guerra ou mercante - os navios de excursões turísticas e os que deslocam pessoas de um porto a outro enquadram-se como mercantes, pois o transporte de pessoas é mercancia; c) que o testador esteja a bordo do navio, em viagem; d) que a cédula testamentária seja registrada em livro diário de bordo, que todos os navios possuem - o registro fará referência ao autor do testamento, à data e a outros dados dignos de nota que ocorrerem; e) que o testamento fique sob a guarda do comandante, que o entregará às autoridades administrativas do primeiro porto nacional (CC, art. 1.890)

O Código Civil Brasileiro de 2002, em seu artigo 1.889, afirma que "quem estiver em viagem, a bordo de aeronave militar ou comercial, pode testar perante pessoa designada pelo comandante, observado o disposto no artigo antecedente". ${ }^{12}$

De acordo Dias, este testamento se submete às mesmas regras do testamento marítimo, podendo, tanto os tripulantes, passageiros, bem como comandante fazerem uso desta prerrogativa, nas modalidades de testamento público ou cerrado. (DIAS, 2013, p. 378)

Até o ano de 2012, as possibilidades de testamentos eram estas então contidas expressamente no ordenamento jurídico, e aqui já referidas, ordinários (público, cerrado e particular) e os especiais (militar, marítimo e aeronáutico), todos já conceituados no decorrer deste item.

12 BRASIL, Código Civil Brasileiro de 2002. Art. 1.889. Quem estiver em viagem, a bordo de aeronave militar ou comercial, pode testar perante pessoa designada pelo comandante, observado o disposto no artigo antecedente. Disponível em http://www.planalto.gov.br/ccivil_03/leis/2002/L10406.htm. 
O Conselho Federal de Medicina, então em 2012, publicou a Resolução n. 1995 em que dispôs sobre as diretivas antecipadas de vontade ou testamento vital, como também são conhecidas pela doutrina.

Trata-se da possibilidade de pacientes manifestarem seus desejos, prévia e expressamente, sobre cuidados e tratamentos que quer, ou não, receber no momento em que estiver incapacitado de expressar, livre e autonomamente, sua própria vontade. ${ }^{13}$

Este tema ainda não é pacífico na doutrina porque muitos autores entendem que não se trata de nova modalidade de testamento em razão das suas particularidades, que serão estudadas no próximo item.

\section{DA RESOLUÇÃO No 1.995 DO CONSELHO FEDERAL DE MEDICINA: INTRODUZIU AS DIRETIVAS ANTECIPA- DAS DE VONTADE}

A resolução n. 1.995 de 2012, do Conselho Federal de Medicina introduziu no Brasil as diretivas antecipadas de vontade, definindo-as como sendo "o conjunto de desejos, prévia e expressamente manifestados pelo paciente, sobre cuidados e tratamentos que quer, ou não, receber no momento em que estiver incapacitado de expressar, livre e autonomamente, sua vontade."14

As diretivas antecipadas de vontade permitem que as famílias e os médicos conduzam a situação e que tomem decisões

13 BRASIL, Resolução n. 1995 de 2012, do Conselho Federal de Medicina. Art. $1^{\circ}$ Definir diretivas antecipadas de vontade como o conjunto de desejos, prévia e expressamente manifestados pelo paciente, sobre cuidados e tratamentos que quer, ou não, receber no momento em que estiver incapacitado de expressar, livre e autonomamente, sua vontade. Disponível em http:// www.portalmedico.org.br/resolucoes/CFM/2012/1995_2012.pdf.

14 BRASIL, Resolução n. 1995 de 2012, do Conselho Federal de Medicina. Art. $1^{\circ}$ Definir diretivas antecipadas de vontade como o conjunto de desejos, prévia e expressamente manifestados pelo paciente, sobre cuidados e tratamentos que quer, ou não, receber no momento em que estiver incapacitado de expressar, livre e autonomamente, sua vontade. Disponível em http:// www.portalmedico.org.br/resolucoes/CFM/2012/1995_2012.pdf. 
acerca de tratamento médico a que será submetido, respeitando a própria vontade do paciente, quando este esteja impossibilitado de externalizá-la, conforme trecho abaixo (ROSA; FARIAS; IBIAS; SILVEIRA, 2013, p. 371):

A declaração antecipada de vontade, expressão que parece refletir melhor significado dessa manifestação, permite que familiares e médicos conduzam a situação e tomem decisões seguindo exatamente o desejo da pessoa que está impossibilitada de exprimir sua vontade, respeitando, com isso, a sua vontade e a sua dignidade.

As diretivas antecipadas de vontade ou testamento vital, como também são conhecidas, são "um negócio jurídico de conteúdo não-patrimonial (existencial)" cujo objetivo é o de estabelecer normas jurídicas sobre determinada matéria de tratamento médico. (BORGES; HIRONAKA; TARTUCE; SIMÃO, 2009, p. 552)

Júnior e Amigo ${ }^{15}$ compartilham da idéia de que as diretivas antecipadas de vontade são um negócio jurídico, em que pese não haja legislação específica sobre o tema ${ }^{16}$, podendo, inclusive, ser estabelecido um contrato entre médico e paciente, conforme se verificar no trecho abaixo:

[...] é possível um contrato entre o paciente e o médico acerca de procedimentos a que se deseja submeter, mas não seria o ideal, uma vez que ao chegar a um estado que não possa expressar sua vontade, ou seja, no momento em que o paciente precisaria usar o contrato, corre o risco do médico não estar mais exercendo sua profissão, o que impossibilitaria a execução do mesmo.

15 JÚNIOR, Aluer Baptista Freire; AMIGO, Andréia Vieira. A legitimidade do testamento vital. Disponível em https://jus.com.br/artigos/26316/a-legitimidade-do-testamento-vital.

16 Para os autores "a falta da norma regulamentadora não desvalida sua concepção, devido à liberdade dos particulares em instituir categoria não contemplada em Lei, na condição de que a mesma não contraponha o ordenamento jurídico. JÚNIOR, Aluer Baptista Freire; AMIGO, Andréia Vieira. A legitimidade do testamento vital. Disponível em https://jus.com.br/ artigos/26316/a-legitimidade-do-testamento-vital. 
Contudo, ao mesmo tempo em que o autor admite a possibilidade de que o paciente e o médico possam estabelecer um contrato, ele ressalta que este contrato não seria o ideal na medida em que poderá deixar de ser cumprido por uma das partes, quando, por exemplo, o médico responsável por determinado paciente deixar de exercer o seu ofício, inviabilizando, portanto, a execução do contrato.

Rosa ${ }^{17}$ demonstra preocupação em relação ao descompasso que poderá haver entre o tempo em que a declaração foi firmada e o momento da incapacidade do paciente, conforme se vê:

A sua principal desvantagem talvez seja o fato de que a vontade declarada pode não ser atual, e isso poderá ter implicações de duas ordens: primeira, avanço da medicina, sendo que uma situação que, antes (no momento da declaração), se apresentava como irreversível ou até mesmo intratável, no futuro, poderá ser administrada como sucesso e sem representar sofrimento para o paciente. Segunda, a mudança da própria vontade ou das convicções do declarante com o transcorrer do tempo, ou em razão do acometimento de uma doença e sua evolução.

De acordo com a autora, a declaração poderá estar totalmente desatualizada, podendo causar prejuízos ao paciente na medida em que a medicina está em constante evolução e o que hoje não há cura, amanhã poderá haver e sem provocar sofrimento ao mesmo, além de poder ocorrer como alerta o autor, uma mudança de pensamento acerca de sua vontade, seja em razão de suas de suas convicções ou até mesmo da evolução de outra doença.

Para Borges, a possibilidade jurídica de elaborar um testamento vital decorre da própria autonomia da vontade, sendo este o seu fundamento jurídico, conforme se vê (BORGES; HIRONAKA; TARTUCE; SIMÃO, 2009, p. 553):

A autonomia privada é o poder atribuído pelo ordenamento jurídico à pessoa para que esta possa reger, com efeitos jurídicos, suas próprias relações.

17 FALTA A NOTA 17 
Esse poder confere às pessoas a possibilidade de regular, por si mesmas, as próprias ações e suas consequencias jurídicas, ou de determinar o conteúdo e os efeitos de suas relações jurídicas, tendo o reconhecimento e podendo contar com a proteção do ordenamento jurídico.

A autonomia privada é, sem dúvida alguma, um importante elemento jurídico, que foi conferido pelo ordenamento às pessoas com o intuito de que estas possam exercê-las em todas as suas relações jurídicas, pois é "sinônimo de autodeterminação, de poder para tomada de decisões". (ROSA; FARIAS; IBIAS; SILVEIRA, 2013, p. 375)

Ainda, de acordo com o autor, o princípio da autonomia é um dos pilares da bioética, cujo objetivo é o resguardar à liberdade individual do paciente, conforme se vê:

O princípio da autonomia, um dos pilares da bioética, visa a assegurar o respeito à liberdade individual da pessoa (do paciente), por se considerar que a própria pessoa deve saber o que é melhor pra si. Portanto, sua decisão deve valer, inclusive, para afastar intervenções médicas. Some-se a esse o princípio da alteridade, também extraído da bioética, segundo o qual se deve buscar entender e respeitar as diferenças entre as pessoas, colocando-se no lugar do outro, experimentando um novo ponto de vista. Perante esses dois princípios, vê-se que a restrição da liberdade de uma pessoa pode configurar ofensa à sua dignidade.

Para Furtado ${ }^{18}$, os princípios da dignidade da pessoa humana, da autonomia e da liberdade são fundamentais para que as pessoas possam exercer de forma ampla o seu direito de fazer suas escolhas sem interferências externas, conforme trecho abaixo:

Há, portanto, estreita relação entre os conceitos de dignidade, autonomia e liberdade. Isso porque, se o fundamento da dignidade de determinada pessoa humana é a sua autonomia em fazer escolhas e exercê-las estreme de qualquer interferência externa, a pessoa humana deve ser livre para

18 FURTADO, Gabriel Rocha. Considerações sobre o testamento vital. Disponível em http://civilistica.com/wp-content/uploads/2015/02/Furtadocivilistica.com-a.2.n.2.2013.pdf. 
que seja digna. 0 oposto da autonomia é a heteronomia. Esta se configura sempre que a liberdade de escolha do sujeito é sombreada e maculada por interferência externa de terceiros.

Note que em que pese o ordenamento privilegie a autonomia privada do indivíduo, a resolução do Conselho Federal de Medicina, em seu artigo $2, \S 2^{\circ}$, preocupou-se em registrar que esta vontade não é absoluta porque o médico pode deixar de levar "consideração as diretivas antecipadas de vontade do paciente ou representante que, em sua análise, estiverem em desacordo com os preceitos ditados pelo Código de Ética Médica." ${ }^{19}$ Contudo, a vontade do paciente prevalecerá "sobre qualquer outro parecer não médico, inclusive sobre os desejos dos familiares. ${ }^{\text {20 }}$

0 parágrafo quinto, também do artigo $2^{\circ}$, adverte que, se não for conhecida eventual vontade do paciente ou de familiares, deve o médico recorrer ao Comitê de Bioética da Instituição, ou, na sua falta ao à Comissão Médica do $\operatorname{Hospital}^{21}$, conforme se vê:

§ 5ํNão sendo conhecidas as diretivas antecipadas de vontade do paciente, nem havendo representante designado, familiares disponíveis ou falta de consenso entre estes, o médico recorrerá ao Comitê de Bioética da instituição, caso exista, ou, na falta deste, à Comissão de Ética Médica do hospital ou ao Conselho Regional e Federal de Medicina para fundamentar sua decisão sobre conflitos éticos, quando entender esta medida necessária e conveniente.

19BRASIL, Resolução n. 1.995 de 2012, do Conselho Federal de Medicina. Art. 2, § 2: § 2을 médico deixará de levar em consideração as diretivas antecipadas de vontade do paciente ou representante que, em sua análise, estiverem em desacordo com os preceitos ditados pelo Código de Ética Médica. Disponível em http://www.portalmedico.org.br/resolucoes/ CFM/2012/1995_2012.pdf.

20 BRASIL, Resolução n. 1.995 de 2012, do Conselho Federal de Medicina. Art. $2, \S 3$ 을 As diretivas antecipadas do paciente prevalecerão sobre qualquer outro parecer não médico, inclusive sobre os desejos dos familiares. Disponível em http://www.portalmedico.org.br/resolucoes/CFM/2012/1995_2012.pdf.

21 BRASIL, Resolução n. 1.995 de 2012, do Conselho Federal de Medicina. Disponível em http://www.portalmedico.org.br/resolucoes/ CFM/2012/1995_2012.pdf. 
O Conselho Federal de Medicina preocupou-se em disciplinar a conduta ética do médico em relação ao eventual desejo de pacientes dizendo que ele deve levar em consideração a vontade do paciente, sem deixar de ressaltar que esta conduta não é absoluta porque pode conflitar com o Código de Ética Médica, que deve ser zelado pelos profissionais da medicina!

Outra preocupação que também merece destaque refere-se à nomenclatura utilizada por alguns juristas sobre este tema. Para Dias a nomenclatura de testamento vital estaria equivocada porque este se difere dos testamentos existentes, conforme se vê (DIAS, 2013, p. 175):

\begin{abstract}
O testamento vital não tem as mesmas características dos testamentos tradicionais, que são disposições para vigorarem após a morte do testador. É preciso que o paciente expresse sua vontade antes de perder a capacidade civil, por meio de escritura pública ou documento particular autêntico, devendo a manifestação estar acompanhado de declaração do médico assistente que ateste sua plena capacidade. 0 documento ser mantido aberto, para o conhecimento da família, dos médicos ou de um amigo. 0 paciente pode nomear um procurador para que tome as providências necessárias ao cumprimento das suas determinações. (grifo da autora)
\end{abstract}

Em razão de o testamento vital diferenciar-se dos demais testamentos previstos na legislação brasileira é que alguns autores preferem tratá-lo como diretivas antecipadas de vontade. Para Ribeiro, o testamento vital seria a nomenclatura adequada para pacientes que dispusessem sobre sua vontade quando acometidos de doença terminal (ocorrerá o evento morte), enquanto as diretivas antecipadas de vontade seria o documento hábil para pacientes que estivessem acometidos de doenças em geral, em que poderiam se recuperar ou não (pode ou não ocorrer o evento morte), mas que o impossibilitasse de exprimir sua própria vontade. (DIAS, 2013, p. 385 apud RIBEIRO; PEREIRA, 2006, p. 276)

Para Borges o ideal na verdade seria até outra nomenclatura e, segundo o mesmo, até há um consenso sobre isto, contudo, 
acredita-se ser improvável que aconteça, conforme se vê (BORGES; HIRONAKA; TARTUCE; SIMÃO, 2009, p. 553):

\begin{abstract}
Sugerem-se outros nomes para essa manifestação de vontade, como declaração antecipada de vontade, manifestação de vontade antecipada, diretivas antecipadas documentos de instruções prévias, documento de vontades antecipadas, diretrizes antecipadas de vida; Apesar disso, seguem-se utilizando as citadas acima. Um novo nome é o ideal, e até parece haver um consenso sobre isso, mas adoção prática de uma outra denominação é, ainda, improvável.
\end{abstract}

As nomenclaturas citadas pelo autor mais utilizadas nas obras e em publicações disponíveis na internet são diretivas antecipadas de vontade, nome dado pela Resolução do Conselho Federal de Medicina e testamento vital, "por este estar se tornando majoritário e amplamente aceito pela doutrina de língua portuguesa". 22 É por isto que foram utilizadas apenas estas duas nomenclaturas no decorrer deste artigo!

É muito importante mencionar ainda que a Resolução n. 1.995 do Conselho Federal de Medicina não fez previsão de forma específica para formalização da vontade do paciente, limitando-se apenas a dizer em seu Art. 2, § 4ํque "o médico registrará, no prontuário, as diretivas antecipadas de vontade que lhes foram diretamente comunicadas pelo paciente".

Em que pese à resolução não tenha previsto que as mesmas tenham de ser realizadas "por meio de escritura pública ou documento particular autêntico, devendo a manifestação estar acompanhado de declaração do médico assistente que ateste sua plena capacidade", conforme o entendimento de Dias, em maio de 2014, o Conselho Nacional de Justiça editou o enunciado n. 37, na I Jornada de Direito da Saúde, na qual dispôs (DIAS, 2013, p. 175):

22 FURTADO, Gabriel Rocha. Considerações sobre o testamento vital. Disponível em http://civilistica.com/wp-content/uploads/2015/02/Furtadocivilistica.com-a.2.n.2.2013.pdf. Acesso realizado em 13 de janeiro de 2016. 
As diretivas ou declarações antecipadas de vontade que especificam os tratamentos médicos que o declarante deseja ou não se submeter quando incapacitado de expressar-se autonomamente, devem ser feitas preferencialmente por escrito, por instrumento particular, com duas testemunhas, ou público, sem prejuízo de outras formas inequívocas de manifestação admitidas em direito. (grifo nosso)

Note que o Conselho Nacional de Justiça optou por utilizar a palavra "preferencialmente" e não "obrigatoriamente, o que significa dizer que serão aceitas outras formas de registro, inclusive, a que foi prevista pela própria resolução do Conselho Nacional de Justiça (prontuário médico).

Contudo, para Rosa o prontuário ou ficha médica "não parece ser a forma mais conveniente para registrar a vontade prévia do paciente, até mesmo para a garantia do profissional da medicina". (ROSA; FARIAS; IBIAS; SILVEIRA, 2013, p. 374)

Como forma a dar maior efetividade às diretivas antecipadas de vontade ou testamento vital, figura introduzida no Brasil pelo Conselho Federal de Medicina, no segundo semestre de 2013 foi criado o primeiro banco privado de registro de testamentos vitais - o RENTEV, "e, desde então, os números de testamentos vitais arquivados nesse registro também tem aumentado."23

De acordo com Segatto ${ }^{24}$, no primeiro semestre de 2015, "256 pessoas registraram o chamado testamento vital nos cartórios do Brasil. No ano passado inteiro, foram lavrados 548 documentos. Os estados com maior número de registros são São Paulo (377), Mato Grosso (86) e Rio Grande do Sul (53).” A discussão sobre a possibilidade de utilizar-se do testamento vital chegou até o Tribunal de Justiça do Rio Grande do Sul, que assim decidiu:

23 SEGATTO, Cristiane. Boas razões para fazer um testamento vital. Disponível em http://saude.ig.com.br/minhasaude/2014-07-17/testamentovital-permite-a-paciente-tomar-as-redeas-da-propria-morte.html.

24 SEGATTO, Cristiane. Boas razões para fazer um testamento vital. Disponível em http://saude.ig.com.br/minhasaude/2014-07-17/testamentovital-permite-a-paciente-tomar-as-redeas-da-propria-morte.html. 
APELAÇÃO CÍVEL. ASSISTÊNCIA À SAÚDE. BIODIREITO. ORTOTANÁSIA. TESTAMENTO VITAL. 1. Se o paciente, com o pé esquerdo necrosado, se nega à amputação, preferindo, conforme laudo psicológico, morrer para "aliviar o sofrimento"; e, conforme laudo psiquiátrico, se encontra em pleno gozo das faculdades mentais, o Estado não pode invadir seu corpo e realizar a cirurgia mutilatória contra a sua vontade, mesmo que seja pelo motivo nobre de salvar sua vida. 2 . 0 caso se insere no denominado biodireito, na dimensão da ortotanásia, que vem a ser a morte no seu devido tempo, sem prolongar a vida por meios artificiais, ou além do que seria o processo natural. 3. 0 direito à vida garantido no art. 5o, caput, deve ser combinado com o princípio da dignidade da pessoa, previsto no art. $2^{\circ}$, III, ambos da CF, isto é, vida com dignidade ou razoável qualidade. A Constituição institui o direito à vida, não o dever à vida, razão pela qual não se admite que o paciente seja obrigado a se submeter a tratamento ou cirurgia, máxime quando mutilatória. Ademais, na esfera infraconstitucional, o fato de o art. 15 do CC proibir tratamento médico ou intervenção cirúrgica quando há risco de vida, não quer dizer que, não havendo risco, ou mesmo quando para salvar a vida, a pessoa pode ser constrangida a tal. 4. Nas circunstâncias, a fim de preservar o médico de eventual acusação de terceiros, tem-se que o paciente, pelo quanto consta nos autos, fez o denominado testamento vital, que figura na Resolução no 1995/2012, do Conselho Federal de Medicina. 5. Apelação desprovida. (Apelação Cível № 70054988266, Primeira Câmara Cível, Tribunal de Justiça do RS, Relator: Irineu Mariani, Julgado em 20/11/2013) (grifo nosso)

Logo, a posição do TJRS, somados aos dados trazidos anteriormente demonstram, sem sombras de dúvidas, a importância da resolução do Conselho Federal de Medicina para introdução do testamento vital no Brasil, mesmo ciente de que ainda é insuficiente porque passados três anos da publicação de tal resolução não houve ainda "um movimento para propositura e aprovação de uma lei específica sobre o testamento vital no Brasil, nos moldes já feitos na Espanha, em Portugal, no Uruguai, entre outros países" o que acaba prejudicando, "a efetividade desse importante direito individual."25

25 SEGATTO, Cristiane. Boas razões para fazer um testamento vital. Disponível em http://saude.ig.com.br/minhasaude/2014-07-17/testamentovital-permite-a-paciente-tomar-as-redeas-da-propria-morte.html. 
4 DA AÇÃO CIVIL PÚBLICA No 1039-86.2013.4.01.3500: AJUIZADA EM FACE DA RESOLUÇÃO No 1.995/2012 DO CONSELHO FEDERAL DE MEDICINA

Em abril de 2013 o Ministério Público Federal - MPF, ajuizou Ação Civil Pública ${ }^{26}$ face ao Conselho Federal de Medicina - CFM, em razão da publicação da Resolução n. 1.995 de 2012, que dispôs sobre as diretivas antecipadas de vontade.

De acordo com o entendimento do MPF trata-se de resolução cujo texto é inconstitucional na medida em que o CFM estaria extrapolando a sua competência ao legislar sobre de matéria que é de competência exclusiva da União, conforme trecho abaixo:

Com efeito, esta demanda tem por objetivo lograr provimento judicial que, em caráter incidental, declare a inconstitucionalidade e ilegalidade da Resolução CFM no 1.995 , de 9 de agosto de 2012, a qual, a pretexto de normatizar a atuação de profissionais da medicina frente à terminalidade da vida de seus pacientes, extravasa os limites do poder regulamentar, impõe riscos à segurança jurídica, alija a família de decisões que lhe são de direito e estabelece instrumento inidôneo para o registro de "diretivas antecipadas de pacientes" (grifo nosso)

A preocupação demonstrada na frase acima colecionada versa sobre três pontos, quais sejam a) 0 CFM legislando sobre matéria que extrapola as suas competências, gerando insegurança jurídica tendo em vista que afronta dispositivo constitucional em que diz que a competência é exclusiva da União; b) o afastamento da família das decisões tomadas pelo paciente ou por representante legal, cabendo aos mesmos apenas respeitar a vontade do paciente e, em caso de ilegalidade buscar junto ao Judiciário o seu saneamento e; por fim, c) a preocupação com a forma com que se dará o registro desta vontade, uma vez que a resolução prevê que o médico poderá registrá-las no próprio prontuário

26 BRASIL, Ação Civil Pública n. 1039-86.2013.4.01.3500, interposta na $1^{\text {a }}$ Vara Federal da Seção Judiciária de Goiás. Disponível em http://testamentovital.com.br/wp-content/uploads/2014/07/senten\%C3\%A7a-ACP-testamento-vital.pdf. 
do paciente, contudo, isto poderá dificultar o acesso a estas informações, bem como a fiscalização dos familiares por tratar-se de documento sigiloso.

O procurador assevera também que tal Resolução não logrou êxito na sua elaboração porque não inseriu em texto como se dará o "estabelecimento dos requisitos relativos ao paciente, limite temporal de validade das diretivas, formas de revogação, critérios de participação da família e instrumento utilizado para o registro da vontade do paciente.

Para Ailton Benedito de Souza, o então procurador, esta resolução muito se assemelha a outra, expedida pelo mesmo órgão, a n. 1.805 de 2006, que estabeleceu, em seu artigo $1^{0}$ o ser "permitido ao médico limitar ou suspender procedimentos e tratamentos que prolonguem a vida do doente em fase terminal, de enfermidade grave e incurável, respeitada a vontade da pessoa ou de seu representante legal".

De acordo com teor de tal resolução, estar-se-ia permitindo a prática da ortotanásia que "significa o não prolongamento artificial do processo de morte, além do que seria o processo natural". São casos em que "o doente já se encontra em processo natural de morte, processo este que recebe uma contribuição do médico no sentido de deixar que esse estado se desenvolva no seu curso natural." (BORGES; HIRONAKA; TARTUCE; SIMÃO, 2009, p.562)

Em 2007 o Ministério Público Federal, através da Ação Civil Pública n. 2007.34.00.014809-3, conseguiu a suspensão dos efeitos da resolução publicada em 2006 por um período de quatro anos, até que foi proferida a decisão da Vara onde tramitou a ação, julgando improcedentes os requerimentos feitos pelo MPF. ( (ROSA; FARIAS; IBIAS; SILVEIRA, 2013, p. 372)

Contudo, para uma melhor compreensão acerca do tema é de suma importância trazer à baila a exposição de motivos ${ }^{27}$

27 BRASIL, Resolução n. 1.995 de 2012 do Conselho Federal de Medicina. Disponível em http://www.portalmedico.org.br/resolucoes/ CFM/2012/1995_2012.pdf. 
utilizada pela Câmara Técnica de Bioética do Conselho Federal de Medicina, que resultou do I Encontro Nacional dos Conselhos de Medicina em 2012, e que motivou a publicação da Resolução publicada em 2012.

Com o objetivo de regulamentar as diretivas antecipadas de vontade dos pacientes que, por alguma incapacidade não pudessem exprimir sua vontade acerca do tratamento médico e diante da necessidade de o CFM disciplinar a conduta dos médicos quando estes se depararem com tais situações, além de reconhecer a importância da autonomia do próprio paciente nesta relação, é que o Conselho Federal de Medicina entendeu que deveria dispor, através de resolução, sobre este tema que ainda é tão polêmico no meio jurídico.

As justificativas basearam-se em cinco pontos específicos, quais sejam a) dificuldade de comunicação do paciente em fim de vida tendo em vista que na grande maioria dos casos de incapacidade "as decisões médicas sobre seu atendimento são adotadas com a participação de outras pessoas que podem desconhecer suas vontades e, em consequencia, desrespeitá-las."; b) receptividade dos médicos às diretivas antecipadas de vontade, demonstrado através de uma pesquisa realizada em Santa Catarina com médicos, advogados e estudantes em que $61 \%$ disseram que respeitariam as vontades previamente estipuladas pelos pacientes; c) receptividade dos pacientes uma vez que muitos consideram uma oportunidade de dispor sobre os cuidados e tratamentos que gostariam que fossem dispensados quando estiverem em incapazes; d) 0 que dizem os códigos de ética da Espanha, Itália e Portugal - são legislações alienígenas que já legislaram sobre o tema e "inseriram, de forma simplificada, o dever de o médico respeitar as diretivas antecipadas do paciente, inclusive verbais" e; e) Comitês de Bioética - alertam os médicos da existência dos Comitês de Bioética que, em que pesem sejam órgãos sem caráter deliberativo, podem auxiliar na tomada de decisões de fim de vida. 
Percebe-se pela leitura da resolução em tela que a preocupação do Conselho Federal de Medicina foi a de tão somente disciplinar a conduta dos médicos que se deparem, em algum momento da sua carreira, com as diretivas de vontade de pacientes, não tendo, portanto, a intenção de usurpar a competência da União para legislar sobre o assunto.

Foi nesse sentido o julgamento da Ação Civil Pública interposta face a Resolução n. 1.995 de 2012. O Juiz Substituto da $1^{\text {a }}$ Vara Federal da Seção Judiciária de Goiás, Eduardo Pereira da Silva, ponderou que em que pese o legislador brasileiro tenha se omitido até o momento de legislar sobre matéria, o Conselho Federal de Medicina não usurpou competência da União, mas se utilizou do vazio legislativo para orientar os médicos sobre as diretivas de vontade que já era realidade no meio médico, tendo em vista que esta prática não é vedada pelo ordenamento jurídico. O Juiz reforçou também que "a resolução tem efeito apenas na relação ético-disciplinar existente entre os Conselhos de Medicina e os médicos, mas não tem o condão de criar direitos ou obrigações, sobretudo nas esferas cíveis e criminais."

Frisou que a família e poder público não estão impedidos de buscar tutela judicial se houver oposição acerca de alguma diretiva de vontade registrada pelo paciente, mas, que em princípio deve prevalecer à vontade do paciente face à dos familiares, contudo, na ausência de diretivas de vontade os familiares podem e devem manifestar suas vontades em relação ao tratamento. Contudo, esclareceu que o fato de a declaração diretiva de vontade ser registrada no prontuário e de o mesmo ser sigiloso não retira dos familiares o direito à informação e que, em caso de violação estes devem acionar o judiciário para acessá-los.

Por fim, em relação à preocupação com o lapso temporal para as diretivas, ressaltou que "nem há que se exigir vigência temporal, já que o paciente está livre para manifestar, a qualquer tempo e por qualquer forma, entendimento diverso sobre o tipo de tratamento a que quer ou não se submeter. 
A Ação Civil Pública foi julgada improcedente em 2014 e está pendente de recurso no Tribunal Regional da 1ㅡㅡ Região, conforme consulta realizada no site do Tribunal. ${ }^{28}$

\section{DAS CONSIDERAÇÕES FINAIS}

0 testamento vital é um grande avanço para a sociedade brasileira, pois privilegia o princípio da dignidade humana, balizador do sistema jurídico vigente, e o princípio da autonomia privada, na medida em que permite que pacientes tenham o direito de manifestar sua vontade acerca de procedimento médico que desejam, ou não, se submeter quando estiverem impossibilitados de exprimi-los.

Trata-se de realidade presente há muito tempo no contexto médico e paciente, contudo, o legislador brasileiro nunca se preocupou em regulamentá-lo, através de lei específica de modo esclarecer os requisitos para utilizar o testamento vital. Sequer houve qualquer movimento do legislativo, ou seja, de quem tem a competência para tanto, de propor projeto de lei sobre o tema.

A publicação da Resolução n. 1.995 de 2012, do Conselho Federal de Medicina, que dispôs sobre as diretivas antecipadas de vontade ou testamento vital, como prefiram chama-la, foi um passo importantíssimo para chamar a atenção da sociedade sobre a realidade que parece passar desapercebida no Brasil.

Obviamente que o que se pretende com a publicação desta resolução não é legislar sobre o testamento vital, até porque faltaria competência ao Conselho Federal de Medicina para tanto, mas, sim orientar médicos acerca da conduta que eles devem adotar diante da manifestação de vontade de seus pacientes.

${ }^{28}$ BRASIL, Site do Tribunal Regional Federal da 1a Região, Consulta realizada em 21 de janeiro de 2016, às 16h44 min. Disponível em http://processual. trf1.jus.br/consultaProcessual/processo.php?trf1_captcha_id=6834321d3dbe4fa0387f2a4e9bc1e4ad\&trf1_captcha=st83\&enviar=Pesquisar\&proc=10398620134013500\&secao $=$ GO. 
Fato é que torna-se imprescindível a elaboração de lei específica que defina os requisitos relativos ao paciente, eventual limite temporal de validade, formas de revogação, critérios de participação da família e instrumento utilizado para o registro da vontade do paciente, para que os pacientes possam efetivar os seus direitos previstos na Carta Magna de 1988, tais como o direito à dignidade humana e a autonomia privada, bem como o seu direito à uma morte digna, e, por conseguinte, sem sofrimento. É preciso, ainda, que haja um consenso em relação a nomenclatura que parece não ser tema pacifico na doutrina. Isto porque alguns doutrinadores entendem que não se trata de nova modalidade de testamento porque não terá como requisito o evento morte, assim como os demais que somente passam a produzir efeitos na esfera jurídica após a morte do testador.

Por fim, em que pese não haver legislação específica sobre o tema e diante da própria posição dos diferentes Tribunais do país é possível afirmar que sim, os pacientes podem utilizar-se das diretivas antecipadas de vontade ou testamento vital, para se manifestarem sobre sua vontade acerca de procedimento médico que desejam, ou não, se submeter quando estiverem impossibilitados de exprimi-los.

\section{REFERÊNCIAS}

ABATE, Alessandra. Os tipos de testamento. Disponível em http:// correiadasilva.com.br/pdf/art_fam/art_fam4.pdf. Acesso realizado em 10 de janeiro de 2016, às $15 \mathrm{~h}$.

BORGES, Roxana Cardoso Brasileiro; HIRONAKA, Giselda Maria Fernandes Noaves (coord.); TARTUCE, Flávio (coord.); SIMÃO, José Fernandes (coord.). Direito de Família e das Sucessões. Rio de Janeiro: Forense, São Paulo: Método, 2009.

BRASIL, Ação Civil Pública n. 1039-86.2013.4.01.3500, interposta na 1a Vara Federal da Seção Judiciária de Goiás. Disponível em http://testamentovital.com.br/wp-content/uploads/2014/07/senten\%C3\%A7a- 
-ACP-testamento-vital.pdf. Acesso em realizado em 11 de janeiro de 2016, às 09h.

BRASIL, Código Civil Brasileiro de 2002. Disponível em http://www. planalto.gov.br/ccivil_03/leis/2002/L10406.htm. Acesso em realizado em 11 de janeiro de 2016, às $15 \mathrm{~h}$.

BRASIL, Resolução n. 1995 de 2012, do Conselho Federal de Medicina. Disponível em Acesso realizado em 10 de janeiro de 2016, às 10h.

BRASIL, Site do Tribunal Regional Federal da 1a Região. Disponível em http://processual.trf1.jus.br/consultaProcessual/processo. php?trf1_captcha_id=6834321d3dbe4fa0387f2a4e9bc1e4ad\&trf1_cap tcha $=$ st83\&enviar $=$ Pesquisar $\&$ proc $=10398620134013500 \&$ secao $=G 0$. Acesso em 16 de janeiro de 2016, às16h44min.

DIAS, Maria Berenice. Manual das sucessões. São Paulo: Editora Revista dos Tribunais, 2013.

DIAS, Maria Berenice. Manual das Sucessões. São Paulo: Revista dos Tribunais, 2013, p. 385 apud RIBEIRO, Diaulas Costa. Um novo testamento: testamentos vitais e diretovas antecipadas. Ins: PEREIRA, Rodrigo da Cunha (coord.). Anais do V Congresso Brasileiro de Direito de Família. Família e dignidade humana. São Paulo: IOB/Thomsom, 2006. p. 276.

FURTADO, Gabriel Rocha. Considerações sobre o testamento vital. Disponível em http://civilistica.com/wp-content/uploads/2015/02/ Furtado-civilistica.com-a.2.n.2.2013.pdf. Acesso em realizado em 11 de janeiro de 2016, às $14 \mathrm{~h}$.

GONÇALVES, Carlos Roberto. Direito civil brasileiro, volume VII: direito das sucessões. São Paulo: Saraiva, 2009.

JÚNIOR, Aluer Baptista Freire; AMIGO, Andréia Vieira. A legitimidade do testamento vital. Disponível em https://jus.com.br/ artigos/26316/a-legitimidade-do-testamento-vital. Acesso em realizado em 14 de janeiro de 2016, às 10h.

RIBEIRO, Regis Rezende. Testamentos e codicilos. Disponível em http://regisrezenderibeiro.jusbrasil.com.br/artigos/115241919/testamentos-e-codicilos. Acesso realizado em 10 de janeiro de 2016, às 13h.

ROSA, Karin Regina Rick Rosa; FARIAS, Cristiano Chaves de [et al.]; IBIAS. Delma Silveira (coord.); SILVEIRA, Diego Oliveira da. Família e Sucessões sob um olhar prático. Porto Alegre: IBDFAM/RS: Letra\&Vida, 2013. 
SEGATTO, Cristiane. Boas razões para fazer um testamento vital. Disponível em http://saude.ig.com.br/minhasaude/2014-07-17/testamento-vital-permite-a-paciente-tomar-as-redeas-da-propria-morte. html. Acesso em realizado em 10 de janeiro de 2016, às $11 \mathrm{~h}$. 